\begin{abstract}
Gender Differences in Aerobic and Work Capacity During Plantar Flexion Exercise by Lindsay Stagner

July, 2009

Director: Timothy Gavin, $\mathrm{PhD}$ DEPARTMENT OF EXERCISE AND SPORT SCIENCE

Maximal oxygen consumption $\left(\mathrm{VO}_{2} \max \right)$ is lower in females compared to males during traditional whole body, systemic exercise. These differences in $\mathrm{VO}_{2}$ max between men and women are still present even after correcting for differences in fat and muscle mass and are due, in part, to central limitations in oxygen delivery in females. Many of these limitations can be avoided by evaluating exercise in an isolated muscle groups.
\end{abstract}

At rest and maximum in the forearm, both men and women have the same relative oxygen consumption and blood flow. There are some differences in the calf at rest; both males and females have the same relative oxygen consumption, however females receive a higher relative blood flow. To investigate if inherent skeletal muscle differences exist between men and women, we measured $\mathrm{VO}_{2}$ and power output during graded treadmill and calf plantar flexion exercise to maximum. It was hypothesized that the relative aerobic and work capacity of the calf would be lower in women compared to men. During treadmill exercise, men had greater absolute $\mathrm{VO}_{2}$ and power output at maximum and when expressed relative to fat free mass (FFM), there was no difference in power output between genders, but differences in $\mathrm{VO}_{2}$ max persisted with men still being higher. During plantar flexion exercise, men again demonstrated greater absolute $\mathrm{VO}_{2}$ and power output at maximum and when expressed relative to calf FFM there was no difference in 
either $\mathrm{VO}_{2}$ or power output between genders. It is concluded that there are no inherent muscle differences in aerobic or work capacity between men and women suggesting that differences in absolute aerobic and work capacity are not due to gender, but rather differences in muscle mass

CCopyright 2009

Gender Differences in Aerobic and Work Capacity During Plantar Flexion Exercise 
Gender Differences in Aerobic and Work Capacity During Plantar Flexion Exercise

\author{
A Thesis Presented to the \\ Faculty of the College of Health and Human Performance \\ East Carolina University
}

In Partial Fulfillment of the Requirements for the

Degree Master of Science in Exercise and Sport Science

By

Lindsay Stagner

July, 2009 
Gender Differences in Aerobic and Work Capacity During Plantar Flexion Exercise

by

Lindsay Stagner

APPROVED BY:

DIRECTOR OF DISSERTATION:

Timothy Gavin, $\mathrm{PhD}$

COMMITTEE MEMBER:

Joe Houmard, $\mathrm{PhD}$

COMMITTEE MEMBER:

Paul DeVita, PhD

COMMITTEE MEMBER:

Wayne Scott, $\mathrm{PhD}$

CHAIR OF THE DEPARTMENT OF EXERCISE AND SPORT SCIENCE:

Stacey Altman, $\mathrm{PhD}$

DEAN OF THE GRADUATE SCHOOL:

Paul J. Gemperline, PhD 
TABLE OF CONTENTS

LIST OF TABLES ..................................................... VII

LIST OF FIGURES ....................................................... VIII

CHAPTER 1: Introduction.............................................

CHAPTER 2: Review of Literature................................................................... 2

Cardiac Limitations.................................................... 3

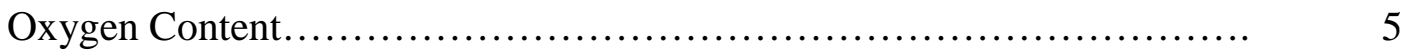

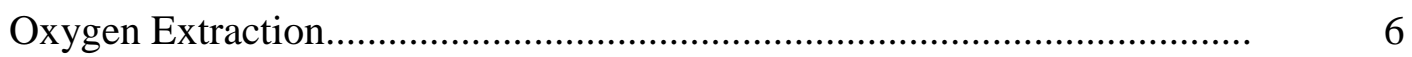

Exercise of Isolated Muscle........................................................

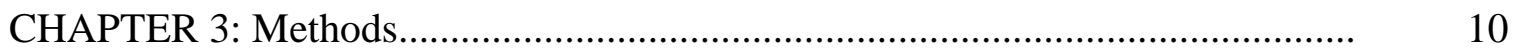

Subjects........................................................... 10

Informed Consent................................................................................

Determination of Fat Free Mass......................................................... 10

Graded Maximal Treadmill Test.....................................................

Graded Maximal Plantar Flexion Exercise................................................... 12

Statistical Analysis................................................... 13

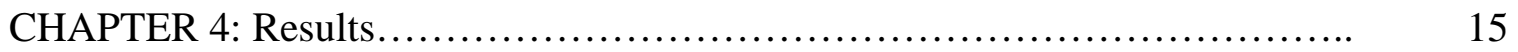

Subject Characteristics.............................................

Graded Maximal Treadmill Test....................................... 15

Graded Maximal Plantar Flexion Exercise............................... 16

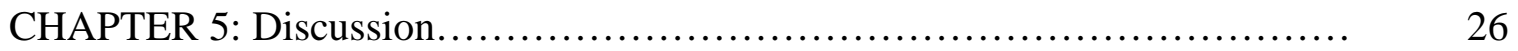

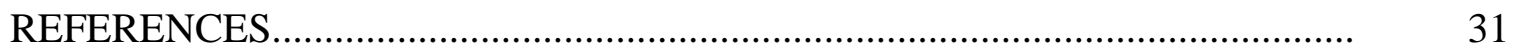




\section{LIST OF TABLES}

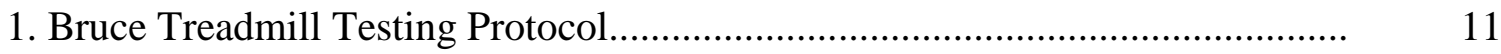

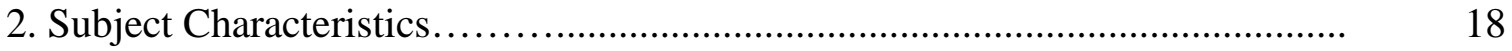

3. Maximal Graded Treadmill Exercise....................................... 19

4. Maximum Graded Plantar Flexion Exercise............................ 20

5. Correlation Coefficients between POmax and $\mathrm{VO}_{2}$

max during Plantar Flexion Exercise................................... 21

6. Correlation Coefficients between POmax during Plantar Flexion

Exercise and Maximal Treadmill Exercise................................ 


\section{LIST OF FIGURES}

1. Maximal Treadmill Power Output and Oxygen Consumption..................... 23

2. Maximum Power Output in Both Legs in Men and Women............................. 24

3. Maximum Power Output and Oxygen Consumption

in Right and Left Legs.................................................. 


\section{CHAPTER 1: INTRODUCTION}

At rest and during aerobic exercise, oxygen is used as the final electron acceptor in the respiratory chain. Maximal oxygen consumption ( $\mathrm{VO}_{2} \max$ ) is a measurement of maximal aerobic capacity. $\mathrm{VO}_{2}$ max is lower in females compared to males during traditional whole body, systemic exercise. Differences in $\mathrm{VO}_{2}$ max between men and women are still present after corrections for differences in fat and muscle mass. These differences are due to central limitations in oxygen delivery resulting from lower cardiac outputs caused by lower stroke volumes and lower oxygen carrying capacities. Oxygen carrying capacity is decreased in women due to lower hemoglobin concentrations. Many of these limitations can be bypassed by evaluating isolated muscle groups. In the forearm at rest and maximum exercise, both men and women have the same oxygen consumption relative to muscle mass $\left(\mathrm{ml} \bullet \mathrm{min}^{-1} \cdot 100 \mathrm{ml}^{-1}\right.$ muscle) $(\mathrm{Jahn}$, Barrett et al. 1999). However, there are some differences between genders in the calf. Both males and females have the same resting relative oxygen consumption $\left(\mathrm{ml} \bullet \mathrm{kgFFM}^{-1} \cdot \mathrm{min}^{-1}\right)$, however, females receive greater resting blood flow relative to fat free mass $\left(\mathrm{ml} \bullet \mathrm{kgFFM}^{-1} \bullet \mathrm{min}^{-1}\right)(\mathrm{Jensen}$, Nguyen et al. 1998). It is unknown if there are any there are differences in $\mathrm{VO}_{2}$ max or power production between genders during calf plantar flexion exercise

In the current study, oxygen consumption and power output were measured during graded maximal plantar flexion exercise and graded treadmill exercise in sedentary men and women. It is hypothesized that the relative aerobic and work capacity of the calf will be lower in women compared to men. 


\section{CHAPTER 2: REVIEW OF LITERATURE}

When expressed in absolute terms, women have approximately $15-25 \%$ lower maximal oxygen consumption $\left(\mathrm{VO}_{2}\right.$ max), however when expressed relative to body weight, women exhibit a 5-15\% difference in $\mathrm{VO}_{2} \max$ (Drinkwater 1973; Cureton, Bishop et al. 1986). Expressing $\mathrm{VO}_{2}$ max relative to body weight lessens the difference in $\mathrm{VO}_{2}$ max which indicates that body mass plays a significant role in differences between men and women.

Typically, women weigh less (Nindl, Scoville et al. 2002; Abe, Kearns et al. 2003; Perez-Gomez, Rodriguez et al. 2008) and have approximately 10\% less muscle mass than men (Maud and Shultz 1986) which contributes to a lower absolute $\mathrm{VO}_{2}$ max . In addition to having less muscle mass, women also have a different distribution of muscle mass. Stepwise regression indicates that the main determinants of appendicular skeletal muscle mass, which includes the upper and lower extremities, are height and weight for which women are shorter and weigh less than men. Arm and leg regional muscle mass distribution comparisons suggest that the gender differences occur throughout the appendicular skeleton (Gallagher, Visser et al. 1997). After controlling for differences in body mass between genders, women have a higher total fat percentage and men have a greater total lean tissue percentage (Nindl, Scoville et al. 2002). Men have greater muscle mass in the arm, while women have more fat distributed to the leg. Men and women have similar values for fat mass in the arms and trunk as well as having the same relative lean tissue distribution between the leg and trunk. 
Average aerobic power output increases with absolute muscle mass (PerezGomez, Rodriguez et al. 2008). Increases in aerobic power with increases in muscle mass are the same for males and females. Due to their inherent lower amount of muscle mass, women have lower absolute aerobic power (Perez-Gomez, Rodriguez et al. 2008). As muscle is the greatest consumer of oxygen during exercise, greater muscle mass in men is responsible in part for their greater absolute $\mathrm{VO}_{2}$ max compared to women.

As succinctly expressed in the Fick equation (Eq 1.), difference in $\mathrm{VO}_{2}$ max must be explained by difference in cardiac output $(\mathrm{CO})$, arterial oxygenation $\left(\mathrm{CaO}_{2}\right)$, and/or mixed venous oxygen content $\left(\mathrm{CvO}_{2}\right)$.

$$
\mathrm{VO}_{2}=\mathrm{CO} \times\left(\mathrm{CaO}_{2}-\mathrm{CvO}_{2}\right)
$$

\section{Cardiac Limitations}

Cardiac output is important in the delivery of oxygen to the organs of the body, including muscle, during exercise. Increasing either heart rate (HR) or stroke volume $(\mathrm{SV})$ increases $\mathrm{CO}$. At rest, $\mathrm{CO}(1 / \mathrm{min})$ is higher in males than in females, however when

expressed relative to body mass $\left(\mathrm{ml} \bullet \mathrm{min}^{-1} \cdot \mathrm{kg}^{-1}\right)$, there is no difference. At rest, there is no difference in heart rate between genders (Wiebe, Gledhill et al. 1998). In general, women are smaller and have smaller hearts when compared to men. Women have a smaller stroke volume at rest which is attributed in part to their smaller heart size (Ogawa, Spina et al. 1992; Charkoudian and Joyner 2004). At rest, women have a lower absolute resting cardiac output due to a lower stroke volume. 
In spite of differences in size, cardiac output is increased by the same mechanisms in response to exercise in both men and women. Increases in stroke volume are limited by heart size in females. At maximum intensity, there is no difference in maximum heart rate; there are differences in maximum absolute stroke volume $(\mathrm{ml} / \mathrm{min})$. However, when expressed in relative terms $\left(\mathrm{ml} \bullet \mathrm{min}^{-1} \bullet \mathrm{kg}^{-1}\right)$, there are no differences in maximum stroke volume between genders (Sullivan, Cobb et al. 1991). Women still have a lower maximal absolute and relative cardiac output. (Wiebe, Gledhill et al. 1998). At workloads resulting in the same percentage of heart rate max, women have a lower cardiac output contributing to lower oxygen consumptions.

Stroke volume is influenced in part by blood volume, which is lower in women (Wiebe, Gledhill et al. 1998). Even when matched for body size, women still have less blood volume (Charkoudian and Joyner 2004). Less blood volume results in less venous return, which according to the Frank-Starling mechanism, leads to lower stroke volume, cardiac output and ultimately oxygen delivery. There is a strong positive correlation between blood volume and $\mathrm{VO}_{2}$ max (Stevenson, Davy et al. 1994; Ferguson, Gledhill et al. 2001). Thus, lower relative blood volumes contribute to lower relative stroke volumes and cardiac outputs in women. In addition, because of their smaller absolute heart volume, there is a limit to which stroke volume can be increased in women. These differences hinder women from achieving the same maximum cardiac output values as men; ultimately lowering oxygen consumption (Ogawa, Spina et al. 1992). Thus, lower blood volume and heart size contribute to lower absolute and relative $\mathrm{VO}_{2}$ max in women compared to men. 


\section{Oxygen Content $\left(\mathrm{CaO}_{2}\right)$}

When $\mathrm{VO}_{2}$ max is corrected for body weight, the difference between genders can be diminished from $15-25 \%$ to $5-10 \%$, but not eliminated. One reason for the remaining difference is a limitation in oxygen carrying capacity of the blood. Oxygen is carried to working muscles in the blood by binding to the iron molecule of hemoglobin unit in a blood cell. On average, women have lower hemoglobin concentration $([\mathrm{Hb}])$ than men (female [13.9g/dL], male [14.3g/dL]) (McArdle 2007). Decreasing male subject's hemoglobin levels similar to a women's content, via blood withdrawal, significantly decreases overall exercise time and oxygen consumption. This decrease in male hemoglobin concentration lowers oxygen consumption $\left(\mathrm{ml} \bullet \mathrm{kg}^{-1} \bullet \mathrm{min}^{-1}\right.$ and $\mathrm{ml} \bullet \mathrm{kg} \mathrm{FFM}^{-1}$

$\cdot \mathrm{min}^{-1}$ ) to that of females (Cureton, Bishop et al. 1986). These results suggest that decreased hemoglobin concentration in women limit oxygen availability which lowers aerobic performance.

Diminished oxygen carrying capacity in women due to lower hemoglobin concentrations has been shown to be improved through iron supplementation. When iron deficient subjects are given an iron supplement for eight weeks, oxygen consumption and endurance time increase compared to pre-supplement values (LaManca and Haymes 1993); suggesting that oxygen consumption was limited by delivery. However, the results on the effect of iron supplementation on improvements in [Hb] and $\mathrm{VO}_{2}$ max are equivocal. Other studies found that in spite of increase in $[\mathrm{Hb}]$, through supplementation, there was not a significant increase in $\mathrm{VO}_{2}$ max compared to that of the placebo group 
(Klingshirn, Pate et al. 1992). These results imply that even when oxygen transport is increased, oxygen consumption is limited by some other variable.

During submaximal exercise, $[\mathrm{Hb}]$ can be compensated by further increases in limb blood flow such that oxygen delivery and oxygen consumption are unaffected (Koskolou, Roach et al. 1997) However, at maximum exercise when limb blood flow is also maximum due to a limit in $\mathrm{CO}$, low $[\mathrm{Hb}]$ results in a lower $\mathrm{VO}_{2}$ max. Thus, low $[\mathrm{Hb}]$ contributes to lower $\mathrm{VO}_{2}$ max in women.

\section{Oxygen Extraction}

Although oxygen delivery $\left(\mathrm{CO}\right.$ and $\left.\mathrm{CaO}_{2}\right)$ is a major influence in the gender difference in oxygen consumption, there is evidence that there is also a difference in venous oxygen saturation $\left(\mathrm{CvO}_{2}\right)$ and muscle oxygen extraction $\left(\mathrm{CaO}_{2}-\mathrm{CvO}_{2}\right)$. At rest and during exercise, men have significantly higher arterial oxygen content, due to higher hemoglobin levels. At peak exercise, men have a lower venous oxygen saturation status (Sullivan, Cobb et al. 1991). From this evidence, it appears that at maximum exercise, males extract more oxygen out of blood than females allowing them to consume more oxygen. During graded exercise tests, men have a significantly higher systemic arteriovenous oxygen difference which could be due to differences in muscle mass, capillary density of muscle and/or muscle fiber composition (Reybrouck and Fagard 1999). Males have more skeletal muscle, and thus a greater amount of muscle being activated during exercise, resulting in more oxygen extracted from the blood that is returning to the heart (mixed venous) compared to women. When men and women with similar hemoglobin 
levels are maximally tested, men still have higher oxygen consumption values, which are attributed to differences in oxygen transport (central limitations) and musculature (Cureton, Bishop et al. 1986).

Capillaries supply each muscle fiber with oxygen and thus a lower capillary density could limit oxygen delivery to active muscle. Capillaries contribute to oxygen extraction and $\mathrm{CaO}_{2}-\mathrm{CvO}_{2}$ at the level of the muscle. A higher distribution of capillaries is indicative of higher functional capacity, allowing for a better distribution of blood flow to local demand (Andersen and Saltin 1985). Men and women have similar capillary density (capillaries $/ \mathrm{mm}^{2}$ ) (Porter, Stuart et al. 2002) Capillary density thus does not contribute to lower oxygen extraction in women compared to men.

In humans, skeletal muscle is comprised of three types of muscle fiber types, I, IIa and II d/x. Type II d/x fibers, called fast twitch fibers, are capable of contracting fast and forcefully, fatigue quickly and have greater anaerobic capacity. In contrast, type I fibers, or slow twitch fibers, contract at slower velocities and with less force, have a high fatigue resistance, and have greater aerobic capacity. Type IIa fibers are intermediate fibers demonstrating fast contraction velocities, and moderate fatigue resistance with glycolytic and aerobic capacities. Higher oxygen consumption is associated with a higher distribution of slow twitch fibers (McArdle 2007). In the vastus medialus, although all three types of fibers are larger in men than women, there is no gender difference in muscle fiber distribution (Staron, Hagerman et al. 2000) discounting the potential of fiber type differences contributing to differences in oxygen extraction. 


\section{Exercise of Isolated Muscles}

The Fick equation (Eq.2) can also be applied across an isolated muscle mass.

$$
\mathrm{VO}_{2 \text { muscle }}=\mathrm{Q}_{\text {muscle }} \mathrm{X}\left(\mathrm{CaO}_{2}-\mathrm{CvO}_{2 \text { muscle }}\right)
$$

Evaluating exercise of an isolated muscle removes many of the central limitations reducing $\mathrm{VO}_{2}$ max in females. During exercise, muscle blood flow is increased linearly to increase oxygen delivery to meet metabolic demand (Andersen and Saltin 1985). Through changes in vascular tone, increased cardiac output is redistributed down a hierarchy of vessels. At the onset of exercise, there is a rapid increase of blood flow to the exercising limb. Blood has been demonstrated to increase as much as 3-5 fold in isolated muscle (Laughlin 1987). Increases in blood flow during exercise are directed towards newly recruited fibers (Ray and Dudley 1998), suggesting that limb muscle perfusion is matched to increasing muscle recruitment and oxygen demand.

In the forearm there is no difference between genders in relative resting blood flow $\left(\mathrm{ml} \bullet \mathrm{min}^{-1} \bullet 100 \mathrm{ml}^{-1}\right)$ however, males have a greater oxygen uptake when expressed relative to forearm volume $\left(\mathrm{ml} \bullet \mathrm{min}^{-1} \bullet 100 \mathrm{ml}^{-1}\right)$. When consumption is expressed relative to forearm muscle volume $\left(\mathrm{ml} \bullet \mathrm{min}^{-1} \bullet 100 \mathrm{ml}^{-1}\right.$ muscle $)$, there is no significant difference between genders in consumption (Jahn, Barrett et al. 1999). In a small muscle mass, women have the same resting relative blood flow to muscle as men, allowing them to have the same relative oxygen consumption across that muscle.

There is also evidence that blood flow is the same between genders while doing dynamic forearm exercises. At rest and task failure, absolute blood flows were lower in 
women than in men. However, there were no differences in relative blood flows $\left(\mathrm{ml} \bullet \mathrm{min}^{-}\right.$

$\left.{ }^{1} \cdot 100 \mathrm{ml}^{-1}\right)($ Gonzales, Thompson et al. 2007) These results show that forearm blood flow is well matched to work and is independent of gender and vascular occlusion.

There are some variations within the leg. Although women have less muscle mass in the leg compared to men, they receive greater resting blood flow relative to fat free mass $\left(\mathrm{ml} \bullet \mathrm{kgFFM}^{-1} \cdot \mathrm{min}^{-1}\right)$. Even with a greater blood flow relative to fat free mass, women have a lower oxygen extraction rate but the same resting oxygen consumption as men $\left(\mathrm{ml} \bullet \mathrm{kgFFM}^{-1} \bullet \mathrm{min}^{-1}\right)($ Jensen, Nguyen et al. 1998). It is unknown if maximal oxygen consumption and work capacities are different during leg plantar flexion exercise between men and women.

\section{Hypothesis}

It is hypothesized that the relative aerobic and work capacity of the calf would be lower in women compared to men. 


\title{
CHAPTER 3: METHODS
}

\author{
Subjects
}

\section{Inclusion Criteria}

Ten healthy sedentary young (18-30 yr) men and ten healthy sedentary women were included in the study.

\section{Exclusion Criteria}

Subjects were excluded if they were participating in regular exercise (>20 min/day, >3 days/week). A "yes" answer to any of the physical activity readiness questionnaire (PAR-Q) completed by the subject also precluded them from participation in the study (ACSM 2000).

\section{Informed Consent}

After successful recruitment, verbal and written information regarding the purpose and nature of the study was presented to the subject. Informed consent was then obtained from each subject. Following written consent, subjects completed the PAR-Q.

\section{Determination of Fat Free and Fat Mass}

Body composition was determined by dual energy X-ray absorptiometry (DEXA). Fat-free and fat mass were calculated from body mass and body fat percentage. Calf specific muscle mass was determined by DEXA. 


\section{Graded Maximal Treadmill Test}

Subjects performed a progressive graded (Bruce) treadmill test starting at a speed $1.7 \mathrm{mph}$ and a grade of $10 \%$ for three minutes as outlined below (Bruce 1974). During the treadmill test, oxygen consumption $\left(\mathrm{VO}_{2}\right)$ was continuously measured through indirect calorimetry using a ParvoMedics TrueMax 2400 Metabolic Measurement cart (Sandy, UT). Subjects were verbally encouraged to exercise until volitional fatigue. The test was stopped at the subjects' request due to volitional fatigue. Tests that reached an oxygen consumption plateau and/or a respiratory exchange ratio greater than 1.0 were considered valid tests. Power output at maximum (POmax) was calculated using the following equation for the treadmill exercise.

$$
\text { Power }=\text { Weight } \bullet \text { Distance } \bullet \text { Time }^{-1}
$$

Where weight is body weight $(\mathrm{Kg})$, and distance $\bullet$ time- $^{1}$ is vertical meters per minute $\left(\mathrm{m} \bullet \mathrm{min}^{-1}\right)$. Vertical meters per minute was calculated by multiplying final stage speed $\left(\mathrm{m} \bullet \mathrm{min}^{-1}\right)$ by final stage percent grade.

\section{TABLE 1.}

\begin{tabular}{|l|l|l|l|}
\hline Time (min) & Stage & Speed (mph) & Grade (\%) \\
\hline $0: 00-3: 00$ & 1 & 1.7 & 10 \\
\hline $3: 00-6: 00$ & 2 & 2.5 & 12 \\
\hline $6: 00-9: 00$ & 3 & 3.4 & 14 \\
\hline $9: 00-12: 00$ & 4 & 4.2 & 16 \\
\hline
\end{tabular}




\begin{tabular}{|l|l|l|l|}
\hline $12: 00-15: 00$ & 5 & 5.0 & 18 \\
\hline $15: 00-18: 00$ & 6 & 5.5 & 20 \\
\hline $18: 00-21: 00$ & 7 & 6.0 & 22 \\
\hline
\end{tabular}

\section{Graded Maximal Plantar Flexion Exercise}

Calf muscle work capacity was determined during plantar flexion exercise. During the plantar flexion exercise, the foot was secured on a pivoting board. Using the sole of the foot, subjects pressed down on the board. Pressing down on the board moved an attached weight up and down. Subjects performed plantar flexion in the supine position. Subjects were instructed to actively perform plantar flexion with passive release and were verbally encouraged to exercise until volitional fatigue.

The subjects underwent a progressive plantar flexion exercise test to maximum on each leg. The test for each leg started at a workload set at approximately $10 \%$ of subject's body weight. Once the foot was positioned on the pivoting board, subjects were instructed to perform plantar flexion synchronized with a metronome moving the board the same distance with each contraction. Weight displacement was measured using a meter stick. The metronome was set to 60 beats per minute, producing 60 plantar flexions per minute (Yamamoto, Miyata et al. 2007). Subjects exercised at the starting weight for two minutes. Workload increased every minute by adding one pound to the lifted weight until exhaustion, indicated by the inability to move the weight the same distance or keep pace with the metronome. Maximal power output (POmax) was calculated by the equation 


$$
\text { Power }=\text { Weight } \bullet \text { Distance } \bullet \text { Time }^{-1}
$$

$\mathrm{Eq} \cdot 4$

Where weight is the total weight (Kg) lifted, distance is the distance (m) moved and time is in seconds. During the incremental plantar flexion test, oxygen consumption was measured by indirect calorimetry using a ParvoMedics TrueMax 2400 Metabolic Measurement cart (Sandy, UT).

To evaluate the validity of the plantar flexion device, maximum plantar flexion power output using the plantar flexion device was compared to maximum plantar flexion power output using a Humac Norm testing system. The Humac Norm is a biomechanical instrument that can test many joint movements in different resistance modes. The subject was set in supine position, with the right leg and foot in the same position as in the plantar flexion exercise. Plantar flexion movement was evaluated with three repetitions at several different isokinetic speeds, including $30 \%$, 60\%, $90 \%$, and $120 \%$ s. The machine is able to evaluate peak torque $(\mathrm{N} \bullet \mathrm{m})$ and work $(\mathrm{J})$ for each speed. Watts were calculated from the Humac Norm data at $90 \%$ s, by the following calculations:

$$
\begin{array}{ll}
47 \mathrm{~J} / 3 \text { repetitions }=15.7 \mathrm{~J} / \mathrm{rep} & (\text { Calculation } 1) \\
15.7 \mathrm{~J} / 1.333 \mathrm{~s}=11.8 \text { Watts } & \text { (Calculation 2) }
\end{array}
$$

The same subject completed the plantar flexion exercise on the plantar flexion device. Watts were calculated by the following calculations using equation 3:

$$
\frac{(8.165 \mathrm{Kg})\left(9.8 \mathrm{~m} / \mathrm{s}^{2}\right)(0.113 \mathrm{~m})}{0.67 \mathrm{~s}}=13.6 \mathrm{~W} \quad \text { (Calculation 3) }
$$


The plantar flexion results are approximately $15 \%$ greater than the standard Humac Norm. This difference in results is not considered significant, and the plantar flexion is a valid exercise evaluation technique.

\section{Statistical Analysis}

Unpaired student's t-tests were used to identify differences between genders. Multiple linear regression was performed to identify relationships between variables. Statistical significance was set at $\mathrm{p} \leq .05$. 


\section{CHAPTER 4: RESULTS}

\section{Subjects}

Subject characteristics for men and women are in Table 2. There were no gender differences in age or body fat percentage. Males were taller $(1.79 \pm 0.03 \mathrm{~m}$ vs. $1.68 \pm$ $0.02 \mathrm{~m})$, heavier $(77.8 \pm 3.1 \mathrm{~kg}$ vs. $60.3 \pm 1.4 \mathrm{~kg})$ and had a larger body mass index (BMI) $(24.4 \pm 1$ vs. $21.4 \pm 0)$ than women. Male subjects also had significantly greater total body fat free mass $(58.5 \pm 2.4 \mathrm{~kg}$ vs. $42.3 \pm 1.4 \mathrm{~kg}$ ), calf mass (Right leg: $3.1 \pm 0.1$ kg vs. $2.6 \pm 0.1 \mathrm{~kg}$; Left leg: $3.0 \pm 0.1 \mathrm{~kg}$ vs. $2.6 \pm 0.1 \mathrm{~kg}$ ) and calf fat free mass (Right leg: $2.4 \pm 0.1 \mathrm{~kg}$ vs. $1.7 \pm 0.1 \mathrm{~kg}$; Left leg: $2.3 \pm 0.1 \mathrm{~kg}$ vs. $1.7 \pm 0.1 \mathrm{~kg}$ ) than women.

\section{Maximal Graded Treadmill Exercise}

The male subjects had a longer treadmill time compared to women during treadmill exercise (11:55 \pm 0:24 min men; 10:04 \pm 0:24 min women). Males had significantly greater absolute $(3.52 \pm 0.18 \mathrm{~L} / \mathrm{min}$ men; $2.25 \pm 0.13 \mathrm{~L} / \mathrm{min}$ women $)$ and relative $(47.3 \pm 1.5 \mathrm{~mL} / \mathrm{kg} / \mathrm{min}$ men; $37.3 \pm 1.7 \mathrm{~mL} / \mathrm{kg} / \mathrm{min}$ women $) \mathrm{VO}_{2}$ max compared to women. When oxygen consumption was corrected for fat free mass, males continued to have higher oxygen consumption $(62.9 \pm 2 . \mathrm{mL} / \mathrm{kgFFM} / \mathrm{min}$ vs. $53.1 \pm 1.8 \mathrm{~mL} / \mathrm{kg}$ FFM/min). Males also had a significantly higher treadmill power output at maximum $(257 \pm 16 \mathrm{~W}$ vs. $167 \pm 8 \mathrm{~W})$. Correcting for body mass $(3.3 \pm 0.2 \mathrm{~W} / \mathrm{kg}$ vs. $2.8 \pm 0.1$ $\mathrm{W} / \mathrm{kg})$ did not change the difference, however, correcting for fat free mass $(4.2 \pm 0.3$ $\mathrm{W} / \mathrm{kgFFM}$ vs. $4.0 \pm 0.2 \mathrm{~W} / \mathrm{kg}$ FFM) eliminated these differences in treadmill power output (Table 3$)$. 


\section{Graded Maximal Plantar Flexion Exercise}

During the plantar flexion exercise, males had a longer exercise time in both right (9:07 \pm 0:44 min; 7:06 $\pm 0: 29 \mathrm{~min})$ and left legs (9:40 $\pm 0: 26 \mathrm{~min} ;$ 7:34 \pm 0:21 min) compared to women. Both the right and left leg gross oxygen consumption during the plantar flexion exercise were higher in males than females (Table 4). When gross oxygen consumption was corrected for calf mass, left leg gross oxygen consumption remained higher in men compared to women while right leg gross oxygen consumption was no longer significantly different. After correcting gross plantar flexion oxygen consumption for calf fat free mass (FFM), there was no difference between genders in either leg.

Next, net calf maximal $\mathrm{VO}_{2}$ was calculated by subtracting resting $\mathrm{VO}_{2}$ prior to plantar flexion from gross plantar flexion maximal $\mathrm{VO}_{2}$. Both right and left calf net $\mathrm{VO}_{2}$ $\max (\mathrm{L} / \mathrm{min})$ were higher in males than females (Table 4). When net calf maximal $\mathrm{VO}_{2}$ was corrected for calf mass or calf fat free mass differences between genders were eliminated in both legs.

Power output at maximum (POmax) during plantar flexion exercise is in Table 3. There was a significant difference in right calf absolute POmax $(12.2 \pm 0.9 \mathrm{~W}$ men vs. $9.2 \pm 0.8 \mathrm{~W}$ women), but no statistical difference in left calf absolute POmax. To investigate if there is a gender effect on plantar flexion exercise a two-way ANOVA was performed using plantar flexion data from both legs. The ANOVA analysis did reveal a main effect of gender such that absolute POmax was lower in women than men ( $p$ $=0.033$, Figure 2) There was no significant difference in relative POmax corrected for 
calf mass (W/kg) or calf fat free mass (W/kg FFM) between genders (Table 4).

Correcting for calf fat free mass eliminated the differences in max PO $(p=0.477$, Figure

3). Right and left leg absolute POmax were strongly correlated $(r=0.889, p<0.0001$, Figure 4).

Correlations were performed to identify relationships between power output and $\mathrm{VO}_{2}$ max during maximal plantar flexion exercise (Table 5) and between power output during maximal plantar flexion exercise and power output during maximal treadmill exercise (Table 6). There were no significant correlations identified between plantar flexion power output and $\mathrm{VO}_{2}$ max during plantar flexion or power output during treadmill exercise. In contrast, there was a significant correlation during maximal treadmill exercise between power output and $\mathrm{VO}_{2}$ (Figure $3 \mathrm{~A}$ ). 
TABLE 2. -Subject Characteristics

\begin{tabular}{|c|c|c|c|c|}
\hline & & Males & Females & P Value \\
\hline Age, yr & & $21.5 \pm 0.9$ & $21.5 \pm 0.5$ & 1.0 \\
\hline Height, m & & $1.79 \pm 0.03$ & $1.68 \pm 0.02$ & 0.003 \\
\hline Weight, kg & & $77.8 \pm 3.1$ & $60.3 \pm 1.4$ & $<0.001$ \\
\hline Body Fat, \% & & $24.2 \pm 3.0$ & $29.9 \pm 2.0$ & 0.131 \\
\hline BMI & & $24.4 \pm 1.0$ & $21.3 \pm 0.4$ & 0.012 \\
\hline FFM, kg & & $58.5 \pm 2.4$ & $42.3 \pm 1.4$ & $<0.001$ \\
\hline \multirow[t]{2}{*}{ Calf Mass, $\mathrm{kg}$} & $\mathrm{R}$ & $3.1 \pm 0.1$ & $2.6 \pm 0.1$ & $<0.001$ \\
\hline & $\mathrm{L}$ & $3.0 \pm 0.1$ & $2.6 \pm 0.1$ & 0.001 \\
\hline \multirow[t]{2}{*}{ Calf FFM, kg } & $\mathrm{R}$ & $2.4 \pm 0.1$ & $1.7 \pm 0.1$ & $<0.001$ \\
\hline & $\mathrm{L}$ & $2.3 \pm 0.1$ & $1.7 \pm 0.1$ & $<0.001$ \\
\hline
\end{tabular}

Values are expressed as means \pm SEM.

BMI $-($ Body Mass Index $)=$ Body weight $(\mathrm{kg}) \div$ Height $(\mathrm{M})^{2}$

FFM - Fat Free Mass 
TABLE 3.-Maximal Graded Treadmill Exercise

\begin{tabular}{|cccc|}
\hline & Males & Females & P Value \\
\hline \hline Time (min) & $11: 55 \pm 0: 24$ & $10: 04 \pm 0: 24$ & 0.004 \\
$\mathrm{VO}_{2}(\mathrm{~L} / \mathrm{min})$ & $3.5 \pm 0.2$ & $2.3 \pm 0.1$ & $<0.001$ \\
$\mathrm{VO}_{2}(\mathrm{~mL} / \mathrm{kg} / \mathrm{min})$ & $47.3 \pm 1.5$ & $37.3 \pm 1.8$ & 0.001 \\
$\mathrm{VO}_{2}(\mathrm{~mL} / \mathrm{kgFFM} / \mathrm{min})$ & $62.9 \pm 2.2$ & $53.1 \pm 1.8$ & 0.003 \\
$\mathrm{Power}$ Output $(\mathrm{W})$ & $257.0 \pm 16.4$ & $167.2 \pm 8.4$ & $<0.001$ \\
$\mathrm{Power}$ Output $(\mathrm{W} / \mathrm{kg})$ & $3.3 \pm 0.2$ & $2.8 \pm 0.1$ & 0.012 \\
Power Output $(\mathrm{W} / \mathrm{kg}$ FFM) & $4.2 \pm 0.3$ & $4.0 \pm 0.2$ & 0.171 \\
\hline
\end{tabular}

Values are expressed as means \pm SEM.

$\mathrm{VO}_{2}-($ Oxygen Consumption) 
TABLE 4.- Maximum Plantar Flexion Exercise

\begin{tabular}{|c|c|c|c|c|}
\hline & & Males & Females & $\mathrm{P}$ Value \\
\hline \multirow[t]{2}{*}{ Time (min) } & $\mathrm{R}$ & $9: 07 \pm 0: 44$ & $7: 06 \pm 0: 29$ & 0.035 \\
\hline & $\mathrm{L}$ & $9: 40 \pm 0: 26$ & $7: 34 \pm 0: 21$ & 0.002 \\
\hline \multicolumn{5}{|l|}{$\begin{array}{c}\text { Gross Oxygen } \\
\text { Consumption }\left(\mathrm{VO}_{2}\right):\end{array}$} \\
\hline \multirow[t]{2}{*}{$\mathrm{VO}_{2}(\mathrm{~L} / \mathrm{min})$} & $\mathrm{R}$ & $0.92 \pm 0.04$ & $0.70 \pm 0.05$ & 0.001 \\
\hline & $\mathrm{L}$ & $0.93 \pm 0.03$ & $0.67 \pm 0.03$ & $<0.001$ \\
\hline \multirow[t]{2}{*}{$\mathrm{VO}_{2}(\mathrm{~mL} / \mathrm{kg}$ Calf Mass/min) } & $\mathrm{R}$ & $0.30 \pm 0.02$ & $0.28 \pm 0.02$ & 0.276 \\
\hline & $\mathrm{L}$ & $0.34 \pm 0.01$ & $0.26 \pm 0.01$ & 0.006 \\
\hline \multirow[t]{2}{*}{$\mathrm{VO}_{2}(\mathrm{~mL} / \mathrm{kg}$ Calf FFM/min) } & $\mathrm{R}$ & $0.38 \pm 0.02$ & $0.42 \pm 0.03$ & 0.395 \\
\hline & $\mathrm{L}$ & $0.41 \pm 0.02$ & $0.39 \pm 0.02$ & 0.657 \\
\hline \multicolumn{5}{|l|}{$\begin{array}{l}\text { Net Oxygen Consumption } \\
\qquad\left(\mathrm{VO}_{2}\right):\end{array}$} \\
\hline \multirow[t]{2}{*}{$\mathrm{VO}_{2}(\mathrm{~L} / \mathrm{min})$} & $\mathrm{R}$ & $0.55 \pm 0.04$ & $0.37 \pm 0.04$ & 0.008 \\
\hline & $\mathrm{L}$ & $0.54 \pm 0.02$ & $0.39 \pm 0.03$ & 0.001 \\
\hline \multirow[t]{2}{*}{$\mathrm{VO}_{2}(\mathrm{~mL} / \mathrm{kg}$ Calf Mass/min $)$} & $\mathrm{R}$ & $0.18 \pm 0.01$ & $0.15 \pm 0.02$ & 0.183 \\
\hline & $\mathrm{L}$ & $0.18 \pm 0.01$ & $0.15 \pm 0.01$ & 0.098 \\
\hline \multirow[t]{2}{*}{$\mathrm{VO}_{2}(\mathrm{~mL} / \mathrm{kg}$ Calf FFM/min) } & $\mathrm{R}$ & $0.23 \pm 0.02$ & $0.23 \pm 0.03$ & 0.817 \\
\hline & $\mathrm{L}$ & $0.24 \pm 0.01$ & $0.24 \pm 0.02$ & 0.926 \\
\hline \multicolumn{5}{|l|}{ Power Output (POmax): } \\
\hline \multirow[t]{2}{*}{ POmax (W) } & $\mathrm{R}$ & $12.2 \pm 1.0$ & $9.2 \pm 1.0$ & 0.026 \\
\hline & $\mathrm{L}$ & $11.7 \pm 1.0$ & $9.1 \pm 1.0$ & 0.057 \\
\hline \multirow[t]{2}{*}{ POmax (W/kg Calf Mass) } & $\mathrm{R}$ & $4.0 \pm 0.3$ & $3.7 \pm 0.4$ & 0.527 \\
\hline & $\mathrm{L}$ & $3.9 \pm 0.3$ & $3.6 \pm 0.3$ & 0.383 \\
\hline \multirow[t]{2}{*}{ POmax (W/kg Calf FFM) } & $\mathrm{R}$ & $5.1 \pm 0.3$ & $5.5 \pm 0.7$ & 0.511 \\
\hline & $\mathrm{L}$ & $5.0 \pm 0.3$ & $5.5 \pm 0.5$ & 0.481 \\
\hline
\end{tabular}

Net Calf $\mathrm{VO}_{2}=$ Gross Maximal $\mathrm{VO}_{2}-$ Resting $\mathrm{VO}_{2}$

Values are expressed as means \pm SEM 
Table 5. - Correlation coefficients between power output (POmax) and oxygen consumption $\left(\mathrm{VO}_{2}\right)$ during maximal plantar flexion exercise.

\begin{tabular}{|c|ccc|}
\hline & $\begin{array}{c}\text { POmax } \\
(\mathrm{W})\end{array}$ & $\begin{array}{c}\text { POmax } \\
(\mathrm{W} / \mathrm{kg})\end{array}$ & $\begin{array}{c}\text { POmax } \\
(\mathrm{W} / \mathrm{kg} \mathrm{FFM})\end{array}$ \\
\hline \hline Gross $\mathrm{VO}_{2}(\mathrm{ml} / \mathrm{min})$ & 0.283 & 0.058 & -0.129 \\
Gross $\mathrm{VO}_{2}(\mathrm{ml} / \mathrm{kg} / \mathrm{min})$ & 0.021 & 0.118 & 0.012 \\
Gross $\mathrm{VO}_{2}(\mathrm{ml} / \mathrm{kg} \mathrm{FFM} / \mathrm{min})$ & -0.128 & 0.089 & 0.264 \\
$\mathrm{Net}$ & 0.257 & 0.109 & -0.061 \\
$\mathrm{Net}_{2}(\mathrm{ml} / \mathrm{min})$ & & & 0.020 \\
$\mathrm{VO}_{2}(\mathrm{ml} / \mathrm{kg} / \mathrm{min})$ & 0.097 & 0.149 & 0.123 \\
\hline
\end{tabular}

* - significant correlation. 
Table 6. -Correlation coefficients between maximal power output during maximal plantar flexion exercise and maximal treadmill exercise.

\begin{tabular}{|lcc|}
\hline & Plantar Flexion (W) & Plantar Flexion (W/kg FFM) \\
\hline \hline Treadmill (W) & 0.301 & -0.250 \\
Treadmill (W/kg FFM) & 0.151 & 0.024 \\
\hline
\end{tabular}

* - significant correlation. 
FIGURE 1 - Maximal treadmill power output and oxygen consumption.

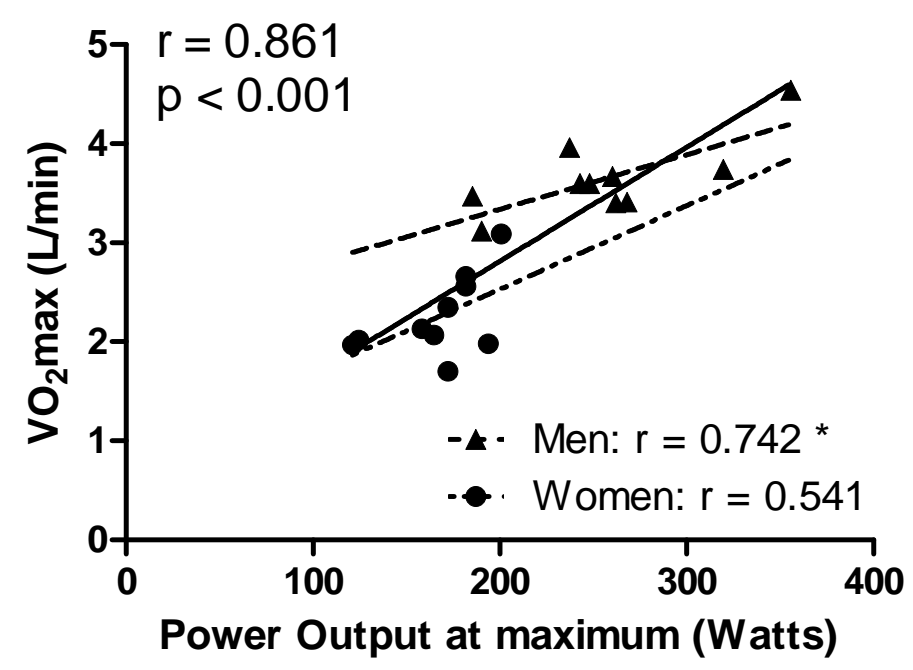

Maximal treadmill workload is correlated with $\mathrm{VO}_{2} \max$. Solid line indicates average of both men and women.

*significant correlation $(\mathrm{p} \leq 0.05)$. 
FIGURE 2 - Maximal power output in both legs in men and women.

\section{Plantar Flexion (W)}

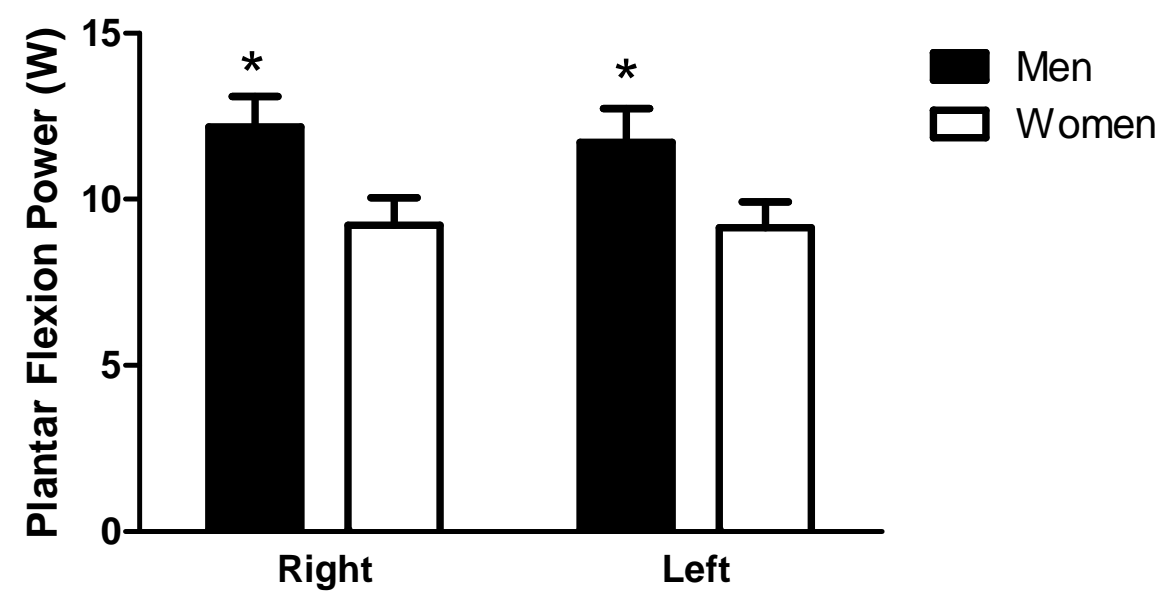

Plantar Flexion power output at maximum (POmax) was significantly different between men and women independent of legs.

Values are mean \pm SEM

* - main effect of gender 
FIGURE 3 - Maximal power output and oxygen consumption in right and left legs.
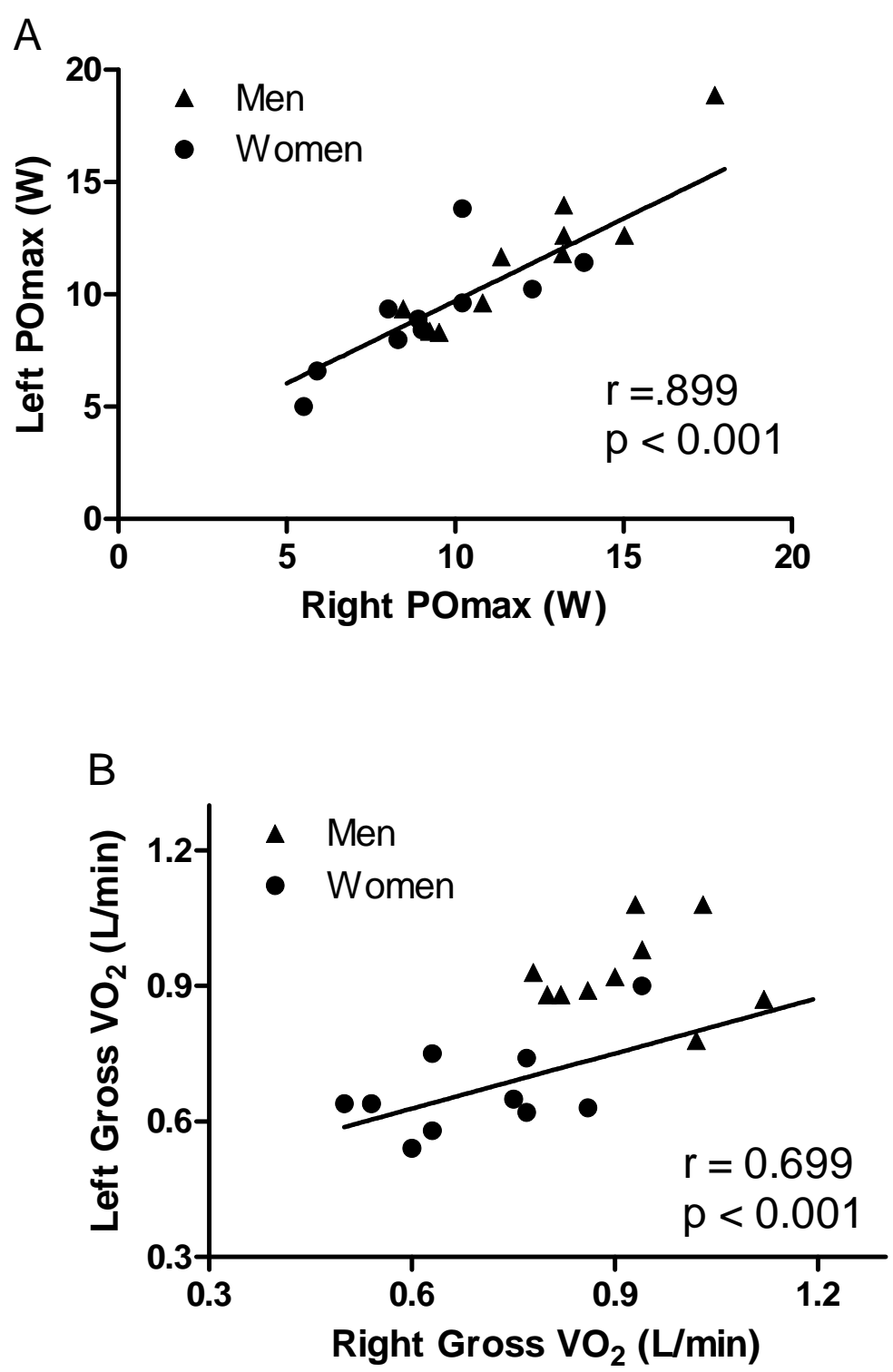

A. . Right leg POmax was correlated with the left. '

B. Right and left leg maximal plantar flexion oxygen consumptions were significantly correlated. 


\section{CHAPTER 5: DISCUSSION}

The main finding in this study was that during lower limb small muscle mass (plantar flexion) exercise, there is a difference in absolute calf maximal power output (POmax) between men and women. However when calf POmax was corrected for calf fat free muscle mass (FFM), this difference between genders was no longer present, refuting the hypothesis. The results from the current study suggest that men and women have the same aerobic and work plantar flexion capacity per unit fat free mass. Consistent with this, during plantar flexion exercise, men had greater gross $(\mathrm{ml} / \mathrm{min})$ and net $\mathrm{VO}_{2} \max$, but these differences were no longer present when corrected for calf FFM also refuting the hypothesis that relative plantar flexion $\mathrm{VO}_{2} \max$ would be lower in females. It was anticipated that during maximal plantar flexion exercise power output would be related to oxygen consumption as was observed during treadmill exercise. Inconsistent with this finding from maximal treadmill exercise, no relationships were identified between power output and oxygen consumption during maximal plantar flexion exercise. It was also anticipated that there would be a positive relationship between treadmill and plantar flexion exercise capacity, however no such relationship was identified.

\section{Subject Characteristics}

It is well known that men have different physical characteristics than women. Typically, men weigh more and have a higher percentage of muscle mass (Nindl, Scoville et al. 2002; Abe, Kearns et al. 2003). In the current study, male subjects were taller, weighed more, and also had a higher BMI. Male subjects had similar body fat 
percentage to that of the female subjects, an unusual finding compared to earlier studies where males have lower body fat percentage (Gallagher, Visser et al. 1997; Nindl, Scoville et al. 2002; Abe, Kearns et al. 2003). This could be a representation of the sedentary subject population chosen for this study or a result of a relatively small sample size.

There was a difference in calf mass and calf fat free mass between genders which confirms results found by others (Gallagher, Visser et al. 1997). This could be due to the characteristics of this subject population, such as age, and limited possibly due to relative small sample size.

\section{Treadmill Exercise Capacity}

Male subjects had higher oxygen consumption, even after correcting for body mass and fat free mass which is similar to results from previous studies ((Drinkwater 1973; Cureton, Bishop et al. 1986). Male subjects also had significantly higher absolute treadmill power output. Correcting for fat free mass eliminated the differences in POmax, confirming results from other studies which demonstrates that power output increases with increases in muscle mass (Perez-Gomez, Rodriguez et al. 2008). The female subjects' absolute power output was thus likely limited by lower muscle mass.

Maximal treadmill power output was correlated with $\mathrm{VO}_{2}$ max. Correcting for body and muscle mass eliminated differences in POmax but not $\mathrm{VO}_{2}$ max. Even with the correction for muscle mass, males continued to have a higher $\mathrm{VO}_{2}$ max. These results suggest that males may consume oxygen less efficiently than women during the treadmill 
exercise; that is that at the same power output, males consume more oxygen. These results are similar to other studies. Kang et. al. observed that men have a higher oxygen consumption slope indicating that they were they became less efficient at the similar treadmill exercise power output compared to women (Kang, Hoffman et al. 2006).

\section{Plantar Flexion Exercise}

During the plantar flexion exercise, male subjects had a significantly higher absolute right leg maximal power output and tended to have a greater left leg maximal power output $(\mathrm{p}=0.057)$ than women. A two-way analysis of variance $($ gender $\times$ leg) was performed to identify if a main effect of gender existed in plantar flexion exercise. The two-way ANOVA revealed a main effect of gender confirming that men generate greater power during maximal plantar flexion exercise than women

When plantar flexion power output was corrected for fat free mass, there was no significant difference in maximal power output between men and women, similar to treadmill data. These data suggest that men and women have the same plantar flexion work capacity per unit calf fat free mass. These findings appear to confirm research from prior studies (Yamamoto, Miyata et al. 2007), however more research is required to investigate if there is a difference in power production between right and left legs in men and women as the current study has found.

Men have greater gross oxygen consumption than women during plantar flexion exercise. Because of their size, men have greater resting $\mathrm{VO}_{2}$ compared to women. To correct for this, net $\mathrm{VO}_{2}$ during plantar flexion was calculated. Men have greater net 
oxygen consumption at maximum during plantar flexion than women. When either gross or net oxygen consumption was corrected for calf mass or the fat free mass of the calf, there were no longer any differences between genders. Thus, when a small muscle mass is exercised, differences between genders are no longer present. This is different than what occurs with treadmill exercise suggesting that efficiency $\left(\mathrm{W} / \mathrm{ml} \mathrm{O}_{2}\right)$ is similar between men and women during small muscle mass exercises. This could indicate that the oxygen consumption evaluation techniques used were not adequate to measure the small responses. However, both right and left maximal plantar flexion oxygen consumption (L/min) as well as maximal power output were significantly correlated (Figure 3 A, B). The correlation between maximal oxygen consumption in right and left legs $(r=0.699, p<0.001)$ suggests that even though the results are different from the treadmill results, oxygen consumption may be an effective evaluation tool during the plantar flexion exercise. The maximal power output correlation between right and left legs also indicates that the plantar flexion exercise was a good evaluation of plantar flexion work capacity.

\section{Conclusion}

In the current investigation, men demonstrated greater absolute $\mathrm{VO}_{2}$ and power output during maximal plantar flexion exercise compared to women. However, when calf POmax was corrected for calf fat free muscle mass (FFM), the differences between genders were no longer present. Differences in plantar flexion work between men and women are thus due to differences in muscle mass and not gender-related differences in 
aerobic exercise. In addition, there was no relationship between treadmill and plantar flexion exercise capacity suggesting that in healthy, young men and women plantar flexion exercise is not a good predictor of whole body exercise capacity. 
Bibliography

Abe, T., C. F. Kearns, et al. (2003). "Sex differences in whole body skeletal muscle mass measured by magnetic resonance imaging and its distribution in young Japanese adults." Br J Sports Med 37(5): 436-40.

ACSM (2000). ACSM's guidelines for exercise testing and prescription. Baltimore, American College of Sports Medicine.

Andersen, P. and B. Saltin (1985). "Maximal perfusion of skeletal muscle in man." J Physiol 366: 233-49.

Bruce, R. A. (1974). "Methods of exercise testing. Step test, bicycle, treadmill, isometrics." Am J Cardiol 33(6): 715-20.

Charkoudian, N. and M. J. Joyner (2004). "Physiologic considerations for exercise performance in women." Clin Chest Med 25(2): 247-55.

Cureton, K., P. Bishop, et al. (1986). "Sex difference in maximal oxygen uptake. Effect of equating haemoglobin concentration." Eur J Appl Physiol Occup Physiol 54(6): 656-60.

Drinkwater, B. L. (1973). "Physiological responses of women to exercise." Exerc Sport Sci Rev 1: 125-53.

Ferguson, S., N. Gledhill, et al. (2001). "Cardiac performance in endurance-trained and moderately active young women." Med Sci Sports Exerc 33(7): 1114-9.

Gallagher, D., M. Visser, et al. (1997). "Appendicular skeletal muscle mass: effects of age, gender, and ethnicity." J Appl Physiol 83(1): 229-39. 
Gonzales, J. U., B. C. Thompson, et al. (2007). "Forearm blood flow follows work rate during submaximal dynamic forearm exercise independent of sex." J Appl Physiol 103(6): 1950-7.

Jahn, L. A., E. J. Barrett, et al. (1999). "Tissue composition affects measures of postabsorptive human skeletal muscle metabolism: comparison across genders." $\mathbf{J}$ Clin Endocrinol Metab 84(3): 1007-10.

Jensen, M. D., T. T. Nguyen, et al. (1998). "Effects of gender on resting leg blood flow: implications for measurement of regional substrate oxidation." J Appl Physiol 84(1): 141-5.

Kang, J., J. R. Hoffman, et al. (2006). "Gender differences in the progression of metabolic responses during incremental exercise." J Sports Med Phys Fitness 46(1): 71-8.

Klingshirn, L. A., R. R. Pate, et al. (1992). "Effect of iron supplementation on endurance capacity in iron-depleted female runners." Med Sci Sports Exerc 24(7): 819-24.

Koskolou, M. D., R. C. Roach, et al. (1997). "Cardiovascular responses to dynamic exercise with acute anemia in humans." Am J Physiol 273(4 Pt 2): H1787-93.

LaManca, J. J. and E. M. Haymes (1993). "Effects of iron repletion on VO2max, endurance, and blood lactate in women." Med Sci Sports Exerc 25(12): 1386-92.

Laughlin, M. H. (1987). "Skeletal muscle blood flow capacity: role of muscle pump in exercise hyperemia." Am J Physiol 253(5 Pt 2): H993-1004.

Maud, P. J. and B. B. Shultz (1986). "Gender comparisons in anaerobic power and anaerobic capacity tests." Br J Sports Med 20(2): 51-4. 
McArdle, W. D., Frank I. Katch, Victor L. Katch (2007). Exercise Physiology: Energy, Nutrition and Human Performance Baltimore, Maryland, Lippincott, Williams and Wilkins.

Nindl, B. C., C. R. Scoville, et al. (2002). "Gender differences in regional body composition and somatotrophic influences of IGF-I and leptin." J Appl Physiol 92(4): 1611-8.

Ogawa, T., R. J. Spina, et al. (1992). "Effects of aging, sex, and physical training on cardiovascular responses to exercise." Circulation 86(2): 494-503.

Perez-Gomez, J., G. V. Rodriguez, et al. (2008). "Role of muscle mass on sprint performance: gender differences?" Eur J Appl Physiol 102(6): 685-94.

Porter, M. M., S. Stuart, et al. (2002). "Capillary supply of the tibialis anterior muscle in young, healthy, and moderately active men and women." J Appl Physiol 92(4): $1451-7$.

Ray, C. A. and G. A. Dudley (1998). "Muscle use during dynamic knee extension: implication for perfusion and metabolism." J Appl Physiol 85(3): 1194-7.

Reybrouck, T. and R. Fagard (1999). "Gender differences in the oxygen transport system during maximal exercise in hypertensive subjects." Chest 115(3): 788-92.

Staron, R. S., F. C. Hagerman, et al. (2000). "Fiber type composition of the vastus lateralis muscle of young men and women." J Histochem Cytochem 48(5): 623-9.

Stevenson, E. T., K. P. Davy, et al. (1994). "Maximal aerobic capacity and total blood volume in highly trained middle-aged and older female endurance athletes." $\underline{\mathbf{J}}$ Appl Physiol 77(4): 1691-6. 
Sullivan, M. J., F. R. Cobb, et al. (1991). "Stroke volume increases by similar mechanisms during upright exercise in normal men and women." Am J Cardiol 67(16): 1405-12.

Wiebe, C. G., N. Gledhill, et al. (1998). "Exercise cardiac function in endurance-trained males versus females." Clin J Sport Med 8(4): 272-9.

Yamamoto, K., T. Miyata, et al. (2007). "Plantar flexion as an alternative to treadmill exercise for evaluating patients with intermittent claudication." Eur J Vasc Endovasc Surg 33(3): 325-9. 


\section{APPENDIX A}

Physical Actialy Preadiness Questomaire - PARQ (revised 2002)

\section{PAR-Q \& YOU}

(A Questionnaire for People Aged 15 to 69)

Regular physical activity is fun and healthy, and increasinghy more people are starting to become more active every day. Being more active is very safe for most people. However, some people should check with their doctor before they start becoming much more physicaly active.

If you are planning to become much more physicaly active than you are now, start by answering the seven questions in the bou below. If you are between the ages of 15 and 69, the PAR-Q will tell you if you should check with your doctor before you start If you are over 69 years of age, and you are not used to being very active, check with your doctor.

Common sense is your best guide when you answer these questions. Please read the questions carefully and answer each ane honestby. check YES or NO.

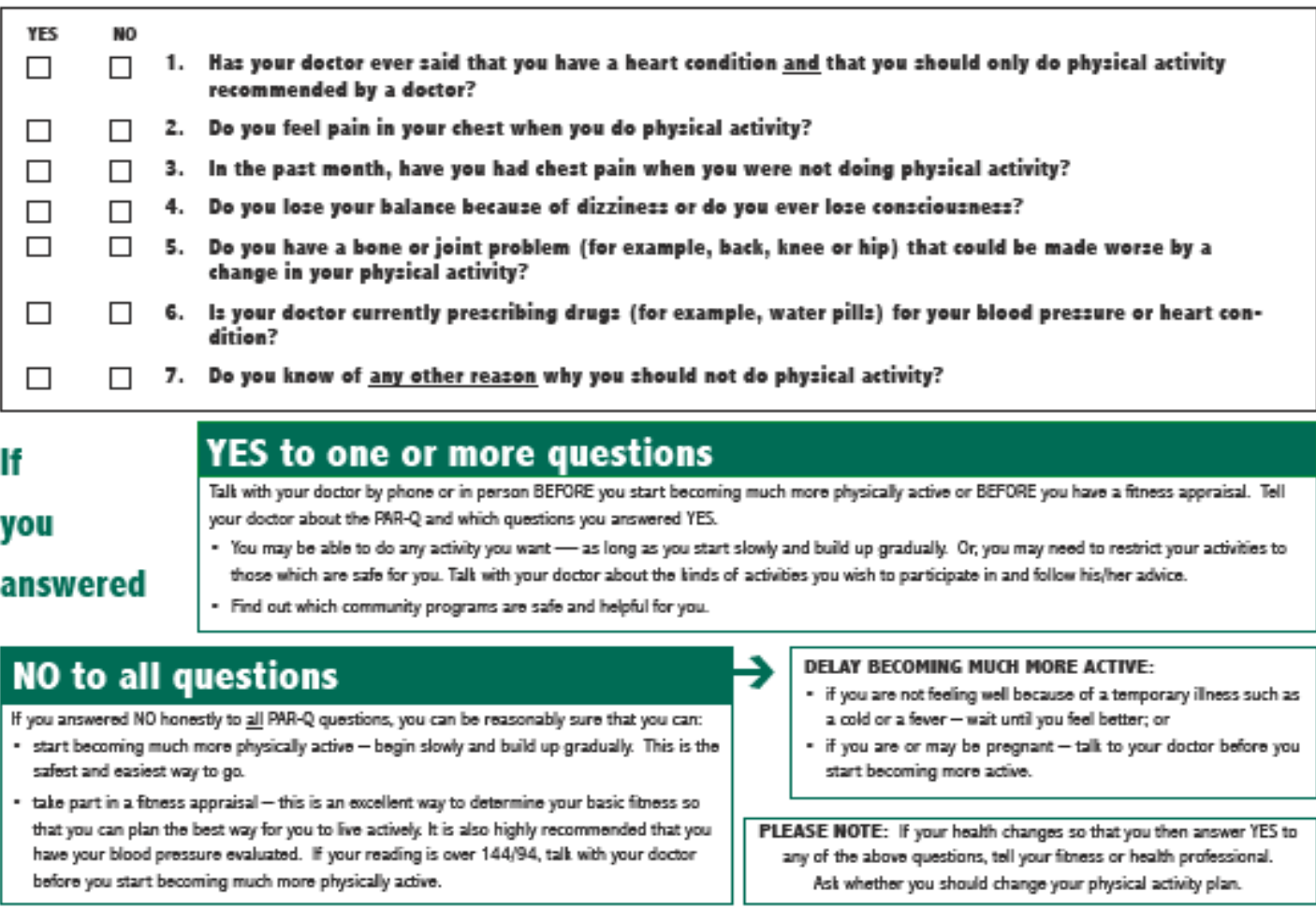

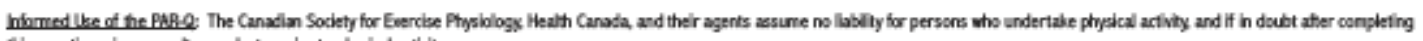
the questionaire, consult your doctor priar to physical actikity.

No changez permitted. You are encouraged to photocopy the PAR-Q but only if you use the entire form.

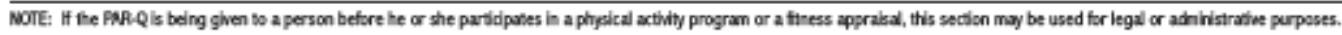

7 have read, understood and completed this questionnaire. Any questions I had were answered to my full satisfaction."

wue

Showure

WWE

SGWWURE OF FVENT

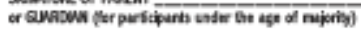

MTMESS

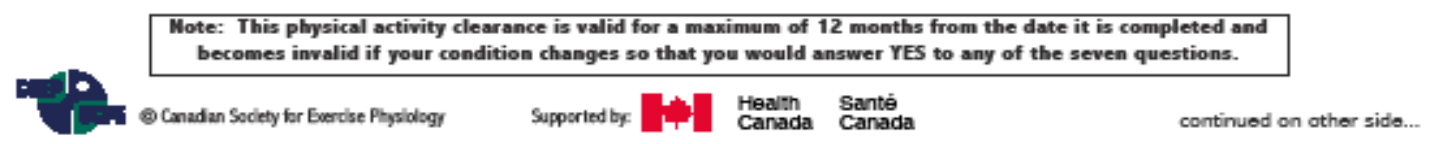




\section{APPENDIX B}

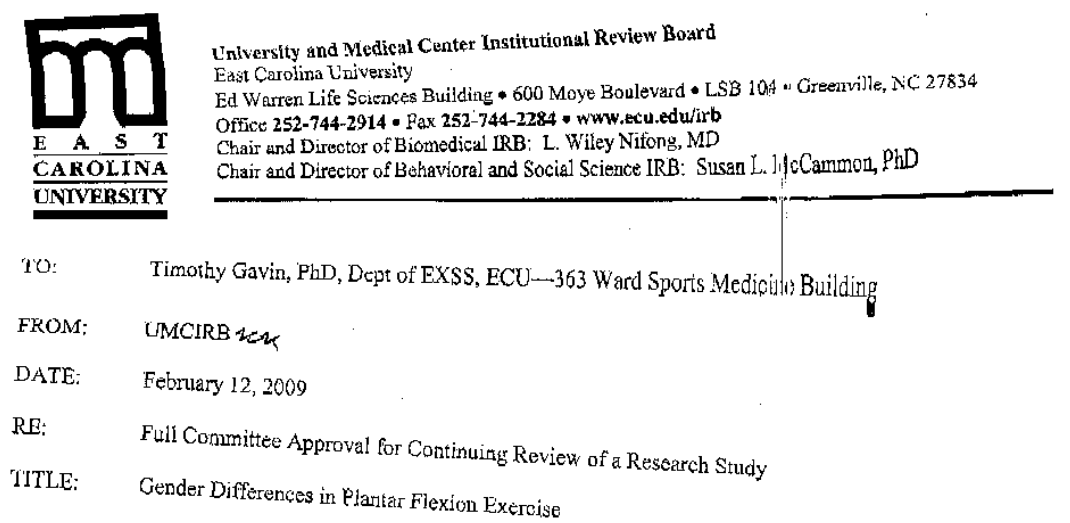

UMCIRE $* 08-0109$

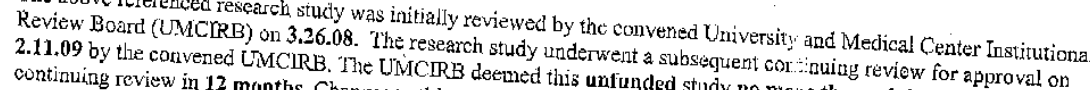

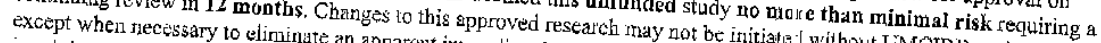
involving risks to participans alle an apparent immediste hazald to the particinatial i without UMCTRB review continuing review/closure ands and others nust be promptly reported to the LMCrob. Al unanticipated probicms to all reporting requirements for thion to the LMCIRB prior to the date of SMCRB, T' 12 investigator must submit a (n) investigator must acthere includes the following itcms.

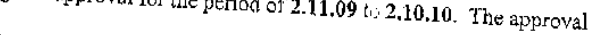

- Protocol

- Informed Consent, Version 1, (dated 1.23 .09 )

- Protocol Descriprion

- Physical Activity Readiness Quesitionnaire (PAR-Q)

The following LMCIRB members were recused for reasons of potential for Conflict of Iniarest on this resetreh study:
Nones NOTE:

None

The CMCIR

funding source. 21 CFR 50 and 21 CFR 56 are applied to all reviewed by the UMCIRB regardless of the

Administration regulution. The UMCIRB follows applieable International Conferenc on Harmonisution Good
Clinical Practice guidelines.

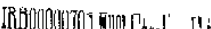

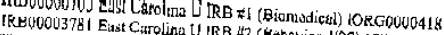

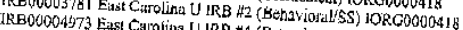

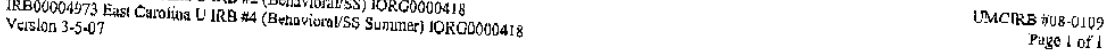




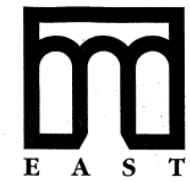

University and Medical Center Institutional Review Board

East Carolina University

Ed Warren Life Sciences Building • 600 Moye Boulevard • LSB $104 \bullet$ Greenville, NC 27834

Office 252-744-2914 • Fax 252-744-2284 • www.ecu.edu/irb

Chair and Director of Biomedical IRB: L. Wiley Nifong, MD

CAROLINA Chair and Director of Behavioral and Social Science IRB: Susan L. McCammon, PhD

UNIVERSITY

TO:

Timothy Gavin, PhD, Dept of EXSS, ECU—363 Ward Sports Medicine Building, ECU

FROM:

UMCIRB そね

DATE: $\quad$ April 28, 2008

RE: $\quad$ Full Committee Approval of a Study

TITLE: "Gender Differences in Plantar Flexion Exercise"

UMCIRB \# 08-0109

The above referenced research study was initially reviewed by the convened University and Medical Center Institutional Review Board (UMCIRB) on 2.13.08 \& 3.26.08. The research study underwent a review and approval of requested modifications on 4.23 .08 by Dr. W. Nifong. The UMCIRB deemed this Human Performance Laboratory sponsored study more than minimal risk requiring a continuing review in $\mathbf{1 2}$ months. Changes to this approved research may not be initiated without UMCIRB review except when necessary to eliminate an apparent immediate hazard to the participant. All unanticipated problems involving risks to participants and others must be promptly reported to the UMCIRB. The investigator must submit a continuing review/closure application to the UMCIRB prior to the date of study expiration. The investigator must adhere to all reporting requirements for this study.

The above referenced research study has been given approval for the period of 3.26.08 to 3.25.09. The approval includes the following items:

-Internal Processing Form

- Protocol (submitted on 3.17.08)

- Informed Consent, Version 1 (dated 4.21.08)

- Physical Activity Readiness Questionnaire (PAR-Q)

- Advertisement

The following UMCIRB members were recused for reasons of potential for Conflict of Interest on this research study: None

NOTE: The following UMCIRB members with a potential Conflict of Interest did not attend this IRB meeting: None

The UMCIRB applies 45 CFR 46, Subparts A-D, to all research reviewed by the UMCIRB regardless of the funding source. 21 CFR 50 and 21 CFR 56 are applied to all research studies under the Food and Drug Administration regulation. The UMCIRB follows applicable International Conference on Harmonisation Good Clinical Practice guidelines. 


\section{INFORMED CONSENT}

\section{Gender differences in plantar flexion exercise}

Principal Investigator: Timothy P. Gavin, Ph.D.

Institution: Human Performance Laboratory

Address: 363 Ward Sports Medicine Building

Telephone \#: (252) 328-4684

\section{INTRODUCTION}

You have been asked to participate in a research study being conducted by Timothy P. Gavin, Ph.D. at East Carolina University.

\section{Why study differences in calf exercise capacity between men and women?}

It is well known that on average, women demonstrate lower maximal oxygen consumption $\left(\mathrm{VO}_{2} \max \right)$ and work capacity compared to men. This is the result of several factors including less muscle mass per unit body mass and lower hemoglobin concentrations. In addition, women demonstrate lower muscle capillarization and lower values for oxidative enzyme, which are important components in setting $\mathrm{VO}_{2}$ max. Whether aerobic or work capacity differences between women compared to men are present when only a small muscle mass such as the calf is exercised is unknown. We hypothesize that aerobic capacity is lower in women during calf exercise compared to men.

We are recruiting 20 healthy individuals (10 men and 10 women). You need to be young (18-30 yrs of age) and sedentary (less than $1 \mathrm{hr}$ of physical activity per week), yet otherwise healthy.

\section{PLAN AND PROCEDURES}

Prior to participation in this project, you will read and sign this Informed Consent for research, as well as complete a physical activity readiness questionnaire (PAR-Q) (included). A "yes" answer to any of these questions will preclude subjects from further participation in the study (American College of Sports Medicine's Guidelines for Exercise Testing and Prescription).

You will arrive at the Human Performance Laboratory (HPL), testing will take approximately 2 hours.

- Determination of fat-free and fat mass. Body composition will be determined by DEXA. The DEXA scan uses low levels of $x$-ray to scan the body which estimates fat mass, lean body mass and bone mass. Fat-free and fat mass will be calculated from body mass and body fat percentage.

- Plantar Flexion Exercise. You be asked to lie on your back, your foot will be strapped to a pivoting board, and you will be asked to perform plantar flexion exercise by pressing down on the board with the sole of your foot. The pivoting board is attached to a weight which will be lifted up and down by performing this action. You will actively perform plantar flexion with passive release. The exercising will begin with a progressive exercise test to determine your maximum. The test will start at a light workload for 2 minutes and the workload will be increased a small increment every 2 minutes until you can no longer continue. You will perform this exercise on each leg.

Page 1 of 5

Subjects initials

Gender differences in plantar flexion exercise Version 1 - 04/21/08

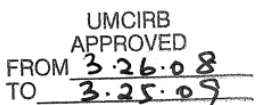


- Exercise test. You will begin by walking on a tread mill at $1.5 \mathrm{mph}$ and $10 \%$ grade. Every three minutes the speed and incline of the treadmill will be increased as outlined in the table below. We will continue to do this until you feel that you can no longer walk because of discomfort. During this test you will be fitted with a mouthpiece through which we can measure the oxygen and carbon dioxide levels that you breathe and the size of the breaths that you take while exercising.

\begin{tabular}{|l|l|l|l|}
\hline Time $(\min )$ & Stage & Speed $(\mathbf{m p h})$ & Grade $(\%)$ \\
\hline $0: 00-3: 00$ & 1 & 1.7 & 10 \\
\hline $3: 00-6: 00$ & 2 & 2.5 & 12 \\
\hline $6: 00-9: 00$ & 3 & 3.4 & 14 \\
\hline $9: 00-12: 00$ & 4 & 4.2 & 16 \\
\hline $12: 00-15: 00$ & 5 & 5.0 & 18 \\
\hline $15: 00-18: 00$ & 6 & 5.5 & 20 \\
\hline $18: 00-21: 00$ & 7 & 6.0 & 22 \\
\hline
\end{tabular}

\section{RISKS AND DISCOMFORTS}

There are risks and discomforts that may be associated with this research. They include:

- Maximal and Sub-maximal Exercise Testing. Risks associated with the exercise to be completed in the current study are dizziness, ventricular arrhythmia (odd heart beats), and in very rare instances death. These risks are very small, with an occurrence of fewer than 1 in 10,000 deaths in patients who are known to, or suspected of, having heart disease. To minimize this risk, an Exercise Physiologist will conduct the maximal exercise test. The maximal exercise test will be stopped if you feel dizzy, are having chest pain, are having serious shortness of breath, or ask that the test be ended. The test will also be stopped if it is detected (from the ECG) that heart function is not normal.

- DEXA Scan. There is a very small amount of radiation from the DEXA scan. The amount is less than you would receive by being outside for a day and 100 times less than you would receive from a chest $\mathrm{x}$-ray.

There may be unforeseen risks involved with this and all research studies.

\section{EXCLUSIONS}

To your knowledge, you do not have any active heart disease, i.e., had a heart attack or worsening chest pain or shortness of breath with exercise. In the last two months, you have not participated in a structured exercise program. You do not perform vigorous physical activity for more than 1 hour per week.

\section{POTENTIAL BENEFITS}

The information gathered from this study may add to the body of knowledge regarding methods to assess exercise capacity in humans. The risks are considered minimal compared to the benefits. 


\section{TERMINATION OF PARTICIPATION}

Your participation in this research study may be terminated without your consent if the investigators believe that the techniques outlined here will pose unnecessary risk to you. You may also be terminated from participation if you do not adhere to the study protocol.

\section{COST AND COMPENSATION}

You will be paid $\$ 25$ for the day of testing. The checks will be mailed out within 4 weeks of completing each phase of the study.

The policy of East Carolina University does not provide for compensation or medical treatment for subjects because of physical or other injury resulting from this research activity. However, every effort will be made to make the facilities of the School of Medicine available for treatment in the event of such physical injury.

\section{CONFIDENTIALITY}

Only the investigators associated with this study will have access to the data obtained. However, the University Medical Center institutional Review Board (UMCIRB), governmental, or university officials may require access to the data to determine if the research outlined here complies with all university and governmental stafutes. Numeric coding will protect your identity. In the reporting of the results, no identifying information will be released.

\section{VOLUNTARY PARTICIPATION}

You understand that your participation in this study is voluntary. Refusal to participate will involve no penalty or loss of benefits to which you am otherwise entitled. Furthermore, you may stop participating at any time you choose without penalty, loss of benefits, or without jeopardizing your continuing medical care at this institution.

\section{PERSONS TO CONTACT WITH QUESTIONS}

The investigators will be available to answer any questions concerning this research, now or in the future. You may contact the investigators, Timothy P. Gavin, Ph.D. at 252-328-4684 or 252-328-4688 (days) or 252-353-9969 (nights and weekends). If questions arise about your rights as a research subject, you may contact the Chairman of the University and Medical Center Institutional Review Board at phone number 252-744-2914 (days). You may contact Risk Management \& Quality Programs at 252-328-2010.

\section{Exclusion Criteria Checklist}

To your knowledge, you (please initial each): Are not ill (sick) today

Do not have active heart disease (have had a heart attack in the last six months, recent worsening of chest pain or increasing shortness of breath on exertion.) Do not vigorously exercise more than 1 hour a week or have been involved in a structured exercise program in the last two months. 


\section{RESEARCH PARTICIPANT AUTHORIZATION TO USE AND DISCLOSE INFORMATION}

Federal laws require that researchers and health care providers protect your identifiable health information. Federal laws atso require that researchers get your permission to use collected health information for research. The identifiable information we will collect from subjects in this research project will include: medications, physical activity levels, body composition information, blood levels of insulin, glucose, lipids, and other compounds related to cardiovascular disease risk.

The members of our research team that will have access to your information will include the Principle Investigator, co-investigators, as well as technical and nursing personnel involved in this project. Information about you will be used and released in such a way that will protect your identity as much as possible; however, confidentiality cannot be absolutely guaranteed. Someone receiving information collected under this Authorization could potentially re-disclose it, and therefore it would no longer be protected under HIPAA privacy rules (federal rules that govern the use and disclosure of your health information. We will only share your information with those individuals listed above. If we need to share information with other individuals other than those listed, we will request your permission a second time.

You will be given a signed copy of your authorization to release medical information for your records. You can limit the amount and type of information that is shared and you must make this request in writing; however, the researcher is able to use any and all information collected prior to the request not to disclose information. Although you can limit the release of your medical information, withholding some information may cause you to become ineligible for this research project. Because research information continues to be looked at after a study is finished, it is difficult to say when the

use of your information will stop. There is currently not an expiration date for the use and disclosure of your information for this study. If a commercial product is developed from this research project, you will not profit from such a product.

Page 4 of 5

Subjects initials

Gender differences in plantar flexion exercise Version 1 -04/21/08 


\section{CONSENT TO PARTICIPATE}

I certify that I have read all of the above, asked questions and received answers concerning areas I did not understand, and have received satisfactory answers to these questions. I willingly give my consent for participation in this research study. Additionally, it is okay with me to use data collected during this study for future studies. (A copy of this consent form will be given to the person signing as the subject or as the subject's authorized representative.)

Subject's Name (Print)

Signature of Subject Time and Date

Signature of Legally Authorized Representative Time and Date

AUDITOR WITNESS: I confirm that the contents of this consent form were orally presented.

Auditor's Name (Print)

Signature of Auditor Witness Time and Date

Timothy P. Gavin, PhD

Principal Investigator's Name (Print)

Signature of Principal Investigator Time and Date

Questions Asked by the Subject (Time and Date)(Continue on back if needed)

Page 5 of 5

Subjects initials

Gender differences in plantar flexion exercise Version 1 - 04/21/08 